\title{
A Comparison of the Operative Techniques and the Postoperative Complications for Bone-Anchored Hearing Aid Implantation
}

\author{
Mark W. Steehler ${ }^{1,2}$ Sean P. Larner ${ }^{1,2,3}$ Joshua S. Mintz ${ }^{4}$ Matthew K. Steehler ${ }^{5}$ Sidney P. Lipman ${ }^{2,3}$ \\ Shane Griffith ${ }^{1,2,3}$ \\ ${ }^{1}$ Department of Otolaryngology, LECOM Health System, \\ Millcreek Community Hospital, Erie, PA, United States \\ ${ }^{2}$ ENT Specialists of Northwestern PA, Erie, PA, United States \\ 3 University of Pittsburgh Medical Center Hamot, Erie, PA, \\ United States \\ ${ }^{4}$ The University of Texas Medical Branch, Galveston, TX, United States \\ ${ }^{5}$ Ear, Nose, and Throat Associates of Corpus Christi, Corpus Christi, \\ TX, United States \\ Int Arch Otorhinolaryngol 2018;22:368-373. \\ Address for correspondence Shane Griffith D.O., M.S. Med, \\ Department of Otolaryngology, UPMC Hamot, 1645 west 8 th street \\ Erie, PA 16505, United States (e-mail: griffithsd2@upmc.edu).
}

\begin{abstract}
Keywords

- hearing aids

- deafness

- otologic surgical procedures

Introduction Bone anchored hearing aids (BAHA) represent a useful surgical option for patients with single sided deafness.

Objectives To compare multiple techniques for BAHA implantation regarding postoperative complications, operative time, and duration between the surgery and the first use of the BAHA.

Methods A retrospective study was conducted of all patients receiving implantation of a BAHA from August of 2008 to October of 2014. Data collected included: patient age, gender, side operated, abutment length, operative time, duration until first use of the BAHA, operative technique, and postoperative complications. The statistical analysis was performed using analysis of variance (ANOVA), Tukey pairwise comparison, chi-square, and paired $t$-test. Statistical significance was determined using a level of $p<0.05$.

Results A total of 88 patients (43 female and 45 male) were included in the data analysis. A total of 80 complications were documented, and these complications were classified according to the Holgers criteria. A significant difference in the total postoperative complications existed between the six techniques used (ANOVA; $p<0.01$ ). In addition, there was also a significant difference among the six techniques employed regarding the operative time (ANOVA; $p<0.01$ ). The average time duration until fitting of the BAHA processor among the various techniques trended toward but did not reach statistical significance (ANOVA; $p=0.16$ ).

Conclusions Significant differences in the operative outcomes exist among the various techniques for BAHA implantation. Based on the statistical analysis of our data, the BAHA Attract system (Cochlear Ltd., Sidney, Australia) requires greater operative time, but it is associated with less postoperative complications than percutaneous techniques and its processor may be fitted significantly sooner.
\end{abstract}

received

August 8, 2017

accepted

November 5, 2017

published online

January 18, 2018
Copyright (e 2018 by Thieme Revinter

Publicações Ltda, Rio de Janeiro, Brazil
License terms

(요 (1) $\circledast$ 


\section{Introduction}

Initially introduced in Sweden in the early 1970s, boneanchored hearing aids (BAHAs) were approved for use in the United States in the late 1990s. ${ }^{1-3}$ Bone-anchored hearing aids are indicated for individuals with conductive or mixed hearing loss when conventional hearing aids are contraindicated or unfeasible, as well as those with single-sided deafness. ${ }^{4,5}$ The device transmits sound from a processor though an osseointegrated titanium implant embedded in the temporal bone, and it stimulates the cochlea through bone conduction. ${ }^{5-7}$ Boneanchored hearing aids have provided significant benefits for individuals who are not candidates for surgery or conventional hearing aids, and have shown improvements in auditory gain of 10 to $25 \mathrm{~dB}$ when compared with traditional bone conduction hearing aids. ${ }^{5,8-11}$

The BAHA consists of a sound processor that attaches to a percutaneous titanium abutment affixed to an osseointegrated titanium fixture. The standard surgical technique for placement of the titanium implant involves the use of pedicled skin grafts and extensive subcutaneous tissue thinning down to the periosteum. ${ }^{12}$ Despite being largely successful, this technique is not without its shortcomings. Multiple variations for placement of the percutaneous BAHA have since been developed, and unfortunately continue to be beleaguered by soft tissue complications, including skin flap necrosis, flap infection, skin growth over the abutment, failure of osseointegration, and extrusion of the titanium implant. ${ }^{13-19}$ To avoid the adverse skin complications and aesthetic concerns associated with the percutaneous BAHA, a new magnetic bone conduction hearing implant system has been developed. ${ }^{20,21}$ Instead of a percutaneous abutment, the magnetic system involves both implanted and external magnets that support the sound processor and transfer sound to the osseointegrated titanium implant. ${ }^{21}$ Recent studies of this new device have shown a favorable adverse event profile and improved cosmesis, with no severe soft tissue complications and only few cases of skin erythema and irritation. ${ }^{21}$

Since 2008, we have employed multiple techniques for BAHA implantation, and have experienced an array of soft tissue complications associated with each technique. In this study, a single surgeon's experience with six different techniques for BAHA implantation is presented. This project's purpose is to compare multiple techniques for BAHA implantation regarding postoperative complications, operative time, and duration between the surgery and the first use of the BAHA. Although various comparisons of BAHA implantation techniques have been performed, no study comparing multiple techniques by a single surgeon exists in the literature. Moreover, this study is unique in that it compares the operative outcomes of both percutaneous and magnetic BAHA implantation techniques.

\section{Materials and Methods}

\section{Cohort}

After the Institutional Review Board (IRB) approval was obtained, a retrospective study was conducted of all patients
Table 1 Holgers classification system for skin reactions at the BAHA implantation site

\begin{tabular}{|l|l|}
\hline Grade & Description \\
\hline 0 & Reaction-free skin around the abutment \\
\hline 1 & $\begin{array}{l}\text { Redness with slight swelling } \\
\text { around the abutment }\end{array}$ \\
\hline 2 & Redness, moistness, and moderate swelling \\
\hline 3 & $\begin{array}{l}\text { Redness, moistness, and moderate } \\
\text { swelling with tissue granulation } \\
\text { around the abutment }\end{array}$ \\
\hline 4 & $\begin{array}{l}\text { Overt signs of infection resulting in } \\
\text { removal of the implant }\end{array}$ \\
\hline
\end{tabular}

receiving implantation of a BAHA from August 2008 to October 2014 by a single surgeon. The system implanted in each case was either the percutaneous Baha Connect or the magnetic Baha Attract (Cochlear Ltd., Sydney, Australia). The medical records were obtained, and the data was collected, including: patient age, gender, side operated, abutment length, operative time, duration until first use of the BAHA, operative technique, and postoperative complications. A complication was defined as an instance that would require additional postoperative care, including steroid or antibiotic treatment, debridement, surgical revision, or implant removal. Soft tissue complications were further classified according to the Holgers classification system (-Table 1). Two cases in the time series reviewed were excluded because of insufficient data. Data was entered into an Excel database spreadsheet (Microsoft Corp., Redmond, WA). The statistical analysis was performed on the collected data using analysis of variance (ANOVA), Tukey pairwise comparison, chisquare, and paired $t$-test. The statistical significance was determined using a level of $p<0.05$.

\section{Surgical Techniques}

All surgeries were performed in a single stage under general anesthesia by a single surgeon. Six different techniques were employed as summarized below. The dermatome technique was the first employed and the Attract technique is the most recent.

\section{Dermatome Technique}

The technique used is as described by Stalfors and Tjellstrom and utilizes a dermatome to create a $0.6 \mathrm{~mm}$ thick and $25 \mathrm{~mm}$ wide anteriorly-based skin flap. ${ }^{18}$ Soft tissue down to the level of the periosteum is debulked and removed and the periosteum is then elevated in the region to accommodate the titanium implant. After securing the implant in the temporal bone, a 4-mm skin-biopsy punch (Miltex Inc., York, PA, USA) is then used to perforate the skin flap over the implant. The skin flap is then threaded over the implant and sutured to the surrounding periosteum. A dressing is applied, and the healing cap is placed over the abutment. The abutment length was not recorded in any cases utilizing the dermatome technique.

\section{U-shaped Flap Technique}

The technique used is as described by Stalfors and Tjellstrom and proceeds similarly to the dermatome technique. ${ }^{18}$ The 
primary difference is that rather than using a dermatome, a scalpel is used to create a 3-4 cm anteriorly based skin flap and debulk the underlying soft tissue to the level of the temporal bone periosteum. The abutment length varied from 4 to $12 \mathrm{~mm}$ among cases utilizing the U-shaped flap technique.

\section{Linear Technique}

The technique used is as described by Mylanus and Cremers and de Wolf et al, and it involves a $3 \mathrm{~cm}$ vertically-oriented incision with soft tissue reduction $2 \mathrm{~cm}$ around the periphery of the incision. ${ }^{22,23}$ The periosteum is elevated, and the implant placed in the standard fashion according to the manufacturer's recommendations. The implant is brought through the incision, and the skin edges are approximated to the periosteum surrounding the implant. A dressing is applied, and the healing cap is placed over the abutment. The abutment length varied from 5.5 to $8.5 \mathrm{~mm}$ among cases utilizing the linear technique.

\section{Linear Technique with Biopsy Punch}

The technique is similar to the linear technique described by de Wolf et al, and is further summarized by Gordon and Coelho. ${ }^{11,23}$ The primary difference is that rather than bringing the implant through the incision, a 4-mm skin-biopsy punch is used to deliver the implant placed just anterior to the vertical incision. The abutment length varied from 5.5 to $9 \mathrm{~mm}$ among cases utilizing the linear technique with biopsy punch.

\section{Biopsy Punch}

The technique used is as described by Wilson and Kim, and it uses a 4-mm skin-biopsy punch to incise the skin and resect the underlying soft tissue and periosteum. ${ }^{5}$ The titanium implant is then placed in the usual fashion, a dressing is applied, and the healing cap is placed over the abutment. An $8.5 \mathrm{~mm}$ abutment was employed in all cases utilizing the biopsy punch technique.

\section{Attract}

The technique used follows the manufacturers guidelines, and is outline by Iseri et $\mathrm{al}^{20} \mathrm{~A} 6 \mathrm{~cm}$ diameter C-shaped incision is utilized to create a full-thickness skin flap. The soft tissue is reduced if measured thicker than $6 \mathrm{~mm}$, and the bone surrounding the implant and internal magnet is smoothed if necessary. Following implantation of the titanium fixture and internal magnet, the skin flap is replaced, the wound is closed primarily with sutures, a drain is placed and a dressing is applied (-Fig. 1).

\section{Results}

A total of 90 patients underwent unilateral BAHA implant surgery during the study period, and 88 ( 43 female, 45 male)
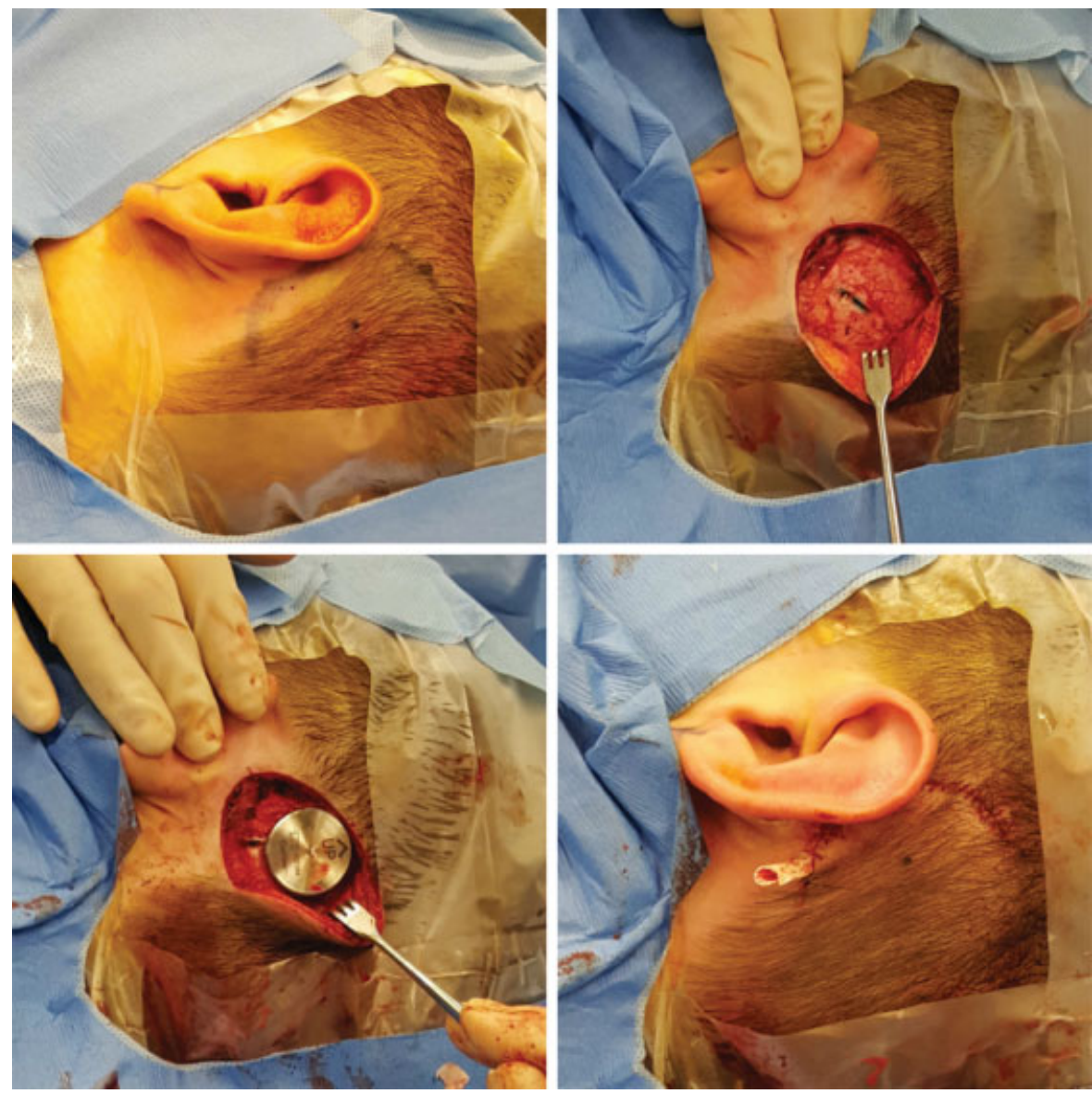

Fig. 1 (A) An 18 gauge needle dipped in methylene blue is used to mark the temporal bone where the implant will be placed. A $3 \mathrm{~cm}$ semi-circle is then marked as the incision site. (B) The flap is taken down to periosteum with soft tissue reduced. (C) The implant is drilled in place with magnet secured in proper position. (D) A drain is placed and the flap is sutured primarily with layered closure. 
Table 2 Comparison of patients undergoing BAHA implantation using various techniques

\begin{tabular}{|l|l|l|l|l|l|l|l|}
\hline Characteristic & Dermatome & Linear & $\begin{array}{l}\text { Biopsy } \\
\text { Punch (BP) }\end{array}$ & $\begin{array}{l}\text { Linear } \\
\text { with BP }\end{array}$ & $\begin{array}{l}\text { U-shaped } \\
\text { Flap }\end{array}$ & Attract & $p$ \\
\hline & $\mathbf{n}=\mathbf{6}$ & $\mathbf{n}=\mathbf{2 5}$ & $\mathbf{n}=\mathbf{6}$ & $\mathbf{n}=\mathbf{1 5}$ & $\mathbf{n}=\mathbf{2 3}$ & $\mathbf{n}=\mathbf{1 3}$ & \\
\hline $\begin{array}{l}\text { Mean age } \\
\text { (years) }\end{array}$ & 54.8 & 55.8 & 60.5 & 58.9 & 59.3 & 56 & $\mathbf{0 . 9 4}$ \\
\hline $\begin{array}{l}\text { Location } \\
\text { (\% right-sided) }\end{array}$ & 50 & 44 & 66.7 & 46.7 & 47.8 & 38.5 & $\mathbf{0 . 9 2}$ \\
\hline $\begin{array}{l}\text { Gender } \\
\text { (\% male) }\end{array}$ & 33.3 & 56 & 83.3 & 60 & 34.8 & 53.8 & $\mathbf{0 . 2 6}$ \\
\hline $\begin{array}{l}\text { Complications } \\
\text { (Total) }\end{array}$ & 6 & 19 & 12 & 20 & 22 & 1 & $<\mathbf{0 . 0 1}$ \\
\hline $\begin{array}{l}\text { Major complications } \\
\text { (Holgers 3 \& 4) }\end{array}$ & 3 & 14 & 6 & 13 & 9 & 0 & $?$ \\
\hline Average. surgical time (min.) & 67 & 54 & 30 & 51 & 41 & 62 & $<\mathbf{0 . 0 1}$ \\
\hline Average. time to 1st use (days) & 90 & 91 & 97 & 88 & 92 & 59 & $\mathbf{0 . 1 6}$ \\
\hline
\end{tabular}

were included in data analysis. The average patient age was 58 years, and the ages ranged from 13 to 83 years. The BAHA implantation was performed on the left side in 47 cases, and on the right side in 41 cases. Six patients underwent the dermatome technique, 25 the linear technique, 6 the biopsy punch technique, 15 the linear technique with biopsy punch, 23 the U-shaped flap, and 13 patients underwent BAHA implantation via the Attract system (-Table 2). The average surgical time and days until fitting of the processor and first use of the BAHA were calculated based on each technique employed and are shown in - Table 2. There were no cases of lost processors and no patient required any change in the strength of the Attract magnet.

There was no statistically significant difference regarding age, side of surgery, gender, or abutment length between the various techniques (-Table 2 ). All postoperative complications were recorded for the cohort. A total of 80 complications were documented, including skin irritation requiring the use of topical steroids, cellulitis around the implant site, overgrowth of skin over the abutment, hematoma formation, granulation tissue requiring debridement, wound dehiscence, and overt infection requiring removal of the implant. These complications were classified based on the Holgers criteria and are shown in -Table 3. A significant difference in the total postoperative complications existed among the six techniques used (ANOVA; $p<0.01$ ). A Tukey pairwise comparison indicated a significant difference between the Attract and biopsy punch techniques. Furthermore, when a direct comparison of the percutaneous and the Attract techniques was analyzed, the total number of postoperative complications was significantly lower for the Attract technique in comparison to the other percutaneous techniques (paired $t$-test; $p<0.01$ ) (-Table 2).

Regarding the operative time, the analysis of the data demonstrated that a significant difference existed between the six techniques employed (ANOVA; $p<0.01$ ). A Tukey pairwise comparison test indicated that the operative time for the biopsy punch technique was significantly shorter than both the Attract and dermatome techniques. When the percutaneous and the Attract techniques were directly compared, the average surgical time was significantly shorter for the percutaneous BAHA implantation (paired $t$-test; $p<0.01$ ).

There was no statistically significant difference between the average duration of time until fitting of the BAHA processor among the various techniques (ANOVA; $p=0.16$ ). When the percutaneous and the Attract techniques were directly compared, though, the average time to fitting of the processor and

Table 3 Soft tissue complications by technique employed

\begin{tabular}{|l|l|l|l|l|l|l|l|}
\hline $\begin{array}{l}\text { Holgers } \\
\text { Classification }\end{array}$ & $\mathbf{1}$ & $\mathbf{2}$ & $\mathbf{3}$ & $\mathbf{4}$ & $\begin{array}{l}\text { Total } \\
\text { Complications }\end{array}$ & $\begin{array}{l}\text { Total } \\
\text { cases }\end{array}$ & $\begin{array}{l}\text { Cases without } \\
\text { complications (\%) }\end{array}$ \\
\hline Dermatome & 2 & 1 & 2 & 1 & 6 & 6 & 50 \\
\hline Linear & 5 & 0 & 9 & 5 & 19 & 25 & 44 \\
\hline Biopsy Punch (BP) & 3 & 3 & 5 & 1 & 12 & 6 & 33.3 \\
\hline Linear with BP & 7 & 0 & 12 & 1 & 20 & 15 & 26.7 \\
\hline U-shaped Flap & 7 & 6 & 8 & 1 & 22 & 23 & 43.5 \\
\hline Attract & 1 & 0 & 0 & 0 & 1 & 13 & 92.3 \\
\hline Total & & & & & 80 & 88 & $\mathbf{4 7 . 7}$ \\
\hline
\end{tabular}


the first use of the BAHA system was significantly shorter for the Attract system (paired $t$-test; $p<0.01$ ).

\section{Discussion}

Since their introduction, the implementation of BAHAs has offered improved auditory performance, and provided an additional option for hearing rehabilitation among individuals that would otherwise be unsuitable candidates for conventional hearing aids. Various techniques for BAHA implantation have been described, with more contemporary approaches attempting to minimize or avoid the high rate of soft-tissue complications seen with other techniques. Nonetheless, softtissue complications continue to vary in severity among patients, and the overall rate of complications differs significantly throughout the literature. According to one review, the overall rate of complications ranged from 15.2 to $88 \%$ among 10 published studies. ${ }^{24}$ What is more, the complication rates reported in relation to a given technique for BAHA implantation have varied among authors. Wilkinson et al experienced a $16.9 \%$ total complication rate in their series of 71 patients implanted with the linear incision technique, whereas de Wolf et al experienced skin reactions in $51 \%$ of their patient population. ${ }^{7,23}$ These findings highlight the difficulty in comparing the complication rates of multiple techniques among various authors, as one must expect significant variability.

In this study, we compared the complication rates and operative times among six different techniques for BAHA implantation performed by a single surgeon. As shown in - Table 3, a total of 80 complications occurred among the 88 procedures performed. Although many patients experienced multiple complications, only $47.7 \%$ of the entire population experienced no soft tissue reactions postoperatively. Moreover, among the percutaneous surgeries, the rate of cases performed without complications was best for the dermatome technique, with only half of the cases experiencing adverse soft-tissue reactions.

In contrast to the high rate of soft-tissue complications among percutaneous BAHA implantations in this and other series, use of the magnetic Attract system resulted in significantly less overall complications in our series. While audiometric outcomes were not established in this study, previous research has shown that with the Attract there is no direct stimulation of the implant, and therefore, there is a loss of energy through the skin at higher frequencies ranging from 10 to $15 \mathrm{~dB} \cdot{ }^{21}$ Indeed, only one complication occurred in the Attract group, and it was classified as a Holgers class 1 complication. In addition, $92.3 \%$ of the Attract cases did not experience any complications. These results are supported by the study conducted by Briggs et al, in which only 4 cases of mild skin erythema were noted in their series of 27 implanted patients, and no major complications occurred. ${ }^{21}$ The erythema noted in each case was likely caused by the pressure exerted by the magnet on the soft-tissues. Although the magnet may be cause irritation due to the pressure exerted, it seems to carry less risk for bacterial seeding and chronic inflammation of the soft tissues than a percutaneous implant.

The analysis of our data demonstrated another advantage of the Attract system in comparison to percutaneous tech- niques for BAHA implantation, which was that the time to fitting the processor was shortest for the Attract population (average time to fitting processor: percutaneous 88-97 days; Attract 59 days). Thus, with the Attract system, the patients have to wait a significantly shorter amount of time until the first use of their BAHA.

Despite the improvement reached on soft-tissue reactions, the Attract technique took significantly longer to perform than one of the percutaneous techniques (avg. time of 62 minutes for the Attract and 30 minutes for biopsy punch). Given the potential reduction in healthcare costs associated with decreased operative time, this finding can have substantial impact. Likewise, a similar finding was made by Gordon and Coelho in demonstrating that the biopsy punch technique could be performed in significantly less time that the linear incision technique. ${ }^{11}$ Thus, when comparing the Attract and biopsy punch techniques, the decreased operative time for the biopsy punch technique must be weighed against its significantly greater risk of soft-tissue reactions.

Several limitations of this study are worthy of mention. Since the Attract technique is the most contemporary of all the BAHA implantation techniques in our series, we have less longitudinal data regarding the care of this patient cohort. Thus, long term complications associated with the implant have yet to be determined. Furthermore, the Attract system would be expected to have a more favorable length of surgery, as it is the most contemporary of the approaches. Even so, it took longer to perform, on average, than most of the percutaneous techniques despite the improvement in the surgical proficiency over time. This further highlights the substantially increased amount of time needed to implant the Attract system. While the audiological results of our cohort were consistent with previously published reports, ${ }^{5,8-11}$ future studies are needed to elucidate whether differences in audiometric outcomes exists between varying BAHA devices and techniques. Lastly, additional variables of cosmesis and postoperative pain were not included in this data analysis, but are important aspects of the BAHA implant surgery and worthy of further study.

\section{Conclusion}

Significant differences in operative outcomes exist among the various techniques for BAHA implantation. Based on the statistical analysis of our data, the Attract system requires longer operative time, but it is associated with less postoperative complications than percutaneous techniques and its processor may be fitted significantly sooner.

Paper Presentation

Accepted for poster presentation at the 2016 Combined Sections Meeting, January 22-24, 2016, Miami Beach, FL.

\section{References}

1 Woolford TJ, Morris DP, Saeed SR, Rothera MP. The implant-site split-skin graft technique for the bone-anchored hearing aid. Clin Otolaryngol Allied Sci 1999;24(03):177-180

2 Mudry A. Bone-anchored hearing aids (BAHA): skin healing process for skin flap technique versus linear incision technique 
in the first three months after the implantation. Rev Laryngol Otol Rhinol (Bord) 2009;130(4-5):281-284

3 Allis TJ, Owen BD, Chen B, Jones DT, Moore GF. Longer length Baha ${ }^{\mathrm{TM}}$ abutments decrease wound complications and revision surgery. Laryngoscope 2014;124(04):989-992

4 Asma A, Ubaidah MA, Hasan SS, et al. Surgical outcome of bone anchored hearing aid (baha) implant surgery: a 10 years experience. Indian J Otolaryngol Head Neck Surg 2013;65(03): 251-254

5 Wilson DF, Kim HH. A minimally invasive technique for the implantation of bone-anchored hearing devices. Otolaryngol Head Neck Surg 2013;149(03):473-477

6 Mylanus EAM, Beynon AJ, Snik AFM, Cremers CWRJ. Percutaneous titanium implantation in the skull for the bone-anchored hearing aid. J Invest Surg 1994;7(04):327-332

7 Wilkinson EP, Luxford WM, Slattery WH III, De la Cruz A, House JW, Fayad JN. Single vertical incision for Baha implant surgery: preliminary results. Otolaryngol Head Neck Surg 2009;140(04): 573-578

8 Hol MK, Snik AF, Mylanus EA, Cremers CW. Does the boneanchored hearing aid have a complementary effect on audiological and subjective outcomes in patients with unilateral conductive hearing loss? Audiol Neurootol 2005;10(03):159-168

9 Badran K, Bunstone D, Arya AK, Suryanarayanan R, Mackinnon N. Patient satisfaction with the bone-anchored hearing aid: a 14-year experience. Otol Neurotol 2006;27(05):659-666

10 Kunst SJ, Hol MK, Mylanus EA, Leijendeckers JM, Snik AF, Cremers $\mathrm{CW}$. Subjective benefit after BAHA system application in patients with congenital unilateral conductive hearing impairment. Otol Neurotol 2008;29(03):353-358

11 Gordon SA, Coelho DH. Minimally invasive surgery for osseointegrated auditory implants: A comparison of linear versus punch techniques. Otolaryngol Head Neck Surg 2015;152(06): 1089-1093

12 Tjellström A, Lindström J, Hallén O, Albrektsson T, Brånemark PI. Osseointegrated titanium implants in the temporal bone. A clinical study on bone-anchored hearing aids. Am J Otol 1981;2 (04):304-310
13 Holgers KM, Bjursten LM, Thomsen P, Ericson LE, Tjellström A. Experience with percutaneous titanium implants in the head and neck: a clinical and histological study.J Invest Surg 1989;2(01):7-16

14 Snyder MC, Moore GF, Johnson PJ. The use of full-thickness skin grafts for the skin-abutment interface around bone-anchored hearing aids. Otol Neurotol 2003;24(02):255-258

15 Lekakis GK, Najuko A, Gluckman PG. Wound related complications following full thickness skin graft versus split thickness skin graft on patients with bone anchored hearing aids. Clin Otolaryngol 2005;30(04):324-327

16 Shirazi MA, Marzo SJ, Leonetti JP. Perioperative complications with the bone-anchored hearing aid. Otolaryngol Head Neck Surg 2006;134(02):236-239

17 House JW, Kutz JW Jr. Bone-anchored hearing aids: incidence and management of postoperative complications. Otol Neurotol 2007; 28(02):213-217

18 Stalfors J, Tjellström A. Skin reactions after BAHA surgery: a comparison between the U-graft technique and the BAHA dermatome. Otol Neurotol 2008;29(08):1109-1114

19 Van Rompaey V, Claes G, Verstraeten N, et al. Skin reactions following BAHA surgery using the skin flap dermatome technique. Eur Arch Otorhinolaryngol 2011;268(03):373-376

20 Işeri M, Orhan KS, Kara A, et al. A new transcutaneous bone anchored hearing device - the Baha ${ }^{\circledR}$ Attract System: the first experience in Turkey. Kulak Burun Bogaz Ihtis Derg 2014;24(02):59-64

21 Briggs R, Van Hasselt A, Luntz M, et al. Clinical performance of a new magnetic bone conduction hearing implant system: results from a prospective, multicenter, clinical investigation. Otol Neurotol 2015;36(05):834-841

22 Mylanus EAM, Cremers CWRJ. A one-stage surgical procedure for placement of percutaneous implants for the bone-anchored hearing aid. J Laryngol Otol 1994;108(12):1031-1035

23 de Wolf MJF, Hol MKS, Huygen PLM, Mylanus EA, Cremers CW. Clinical outcome of the simplified surgical technique for BAHA implantation. Otol Neurotol 2008;29(08):1100-1108

24 Fontaine N, Hemar P, Schultz P, Charpiot A, Debry C. BAHA implant: implantation technique and complications. Eur Ann Otorhinolaryngol Head Neck Dis 2014;131(01):69-74 